\title{
COMPARATIVE EVALUATION OF TREE SPECIES POPULATIONS UNDER DIFFERENT LAND USE TYPES WITHIN THE UNIVERSITY OF PORT HARCOURT ENVIRONS
}

\author{
*Chima UD and Uwaegbulem C \\ Department of Forestry and Wildlife Management, University of Port Harcourt- Choba, Port Harcourt, Rivers \\ State, Nigeria.
}

Accepted : 23 December 2011

ABSTRACT

Impact of land use changes and varying levels of habitat disturbance on tree populations was evaluated using the spatial analogue technique of studying ecosystem dynamics. Three sites with low, moderate, and high levels of disturbance were purposively chosen from the Biodiversity Conservation Area (BCA), an Unprotected Secondary Regrowth (USR), and an Arable Farmland (AF) respectively, for the study. Tree density and alpha diversity were evaluated in each site. The level of tree species compositional similarity/variation was also ascertained for each pair of the sites, and the extent of change in populations of individual tree species measured for the unprotected sites - USR and AF. Total tree density was highest in BCA (466 trees/hectare) followed by USR (317 trees/hectare) and AF (73 trees/hectare). Tree diversity was highest and lowest in BCA and AF respectively. Tree species compositional variation was higher between BCA and each of USR \& AF (66.7\%), than between USR and AF (57.1). Harungana madagascariensis, Berlinia grandiflora, and Eleais guineensis were the most abundant tree species in BCA, USR, and AF, respectively. Although, populations of many tree species were found to be drastically reduced or completely lost in the unprotected sites, improvement was observed in populations of few species with Spondias mombin having the highest improvement index $(314.29 \%)$ in USR while $E$. guineensis had the highest improvement index (72.7\%) in AF. S. mombin is highly valued in the study area because of its edible fruits and diverse medicinal attributes while palm oil and palm kernel oil from $E$. guineensis contribute immensely to rural livelihoods. Hence, the rural dwellers tend to favour and encourage their growth.

Key words: Land use changes, Habitat disturbance, Tree species composition

\section{INTRODUCTION}

Land is used for many purposes. These include farming, fuel, shelter, damming, industrial purposes, mining and others. In the process of achieving these purposes, man changes the terrestrial habitats and thus, affects the life forms - animals, plants and microorganisms, which live in or on them. For instance, the continuous clearing of the forest for shifting cultivation, cattle ranching, timber, fuel wood, road construction, pipe-laying, shelter, mining and industrial purposes have caused the loss and degradation of forests.

Although loss of tree species could occur through other causes, the most important single factor affecting the fate of tree species populations on Earth is the accelerated rate of habitat destruction (Harris 1984). The different farming methods such as shifting cultivation and monoculture and activities like tillage, and fertilizer and pesticide applications, disturb the balance in the ecosystem. The annual burning *Corresponding author: punditzum@yahoo.ca of the trees, shrubs and herbs during shifting cultivation kills off the seedlings of plants and the soil microorganisms, thus leading to their extinction.

Salami (2006), in his study to ascertain the feasibility of the use of NigeriaSat-1 and other satellites in monitoring Nigerian forests, reported that deforestation in Nigeria is occurring at an annual rate of $1.36 \%$, though, the Nigerian Federal Department of Forestry argues that the rate of deforestation in the country is $3.5 \%$ per annum. Conservative estimates of rates of tree species loss suggest that unless current trends are reversed, more than one quarter of the earth's tree species may vanish in the next fifty years (Raven 1988, Ehrlich and Wilson 1991). However, the importance of tree species cannot be over emphasized. Humanity depends on trees for fuel, food, medicine, raw materials, etc. Apart from the various goods and raw materials provided by the forests as listed above, they also provide immense intangible and 


\section{CHIMA UD AND UWAEGBULEM C; TREE SPECIES IN UNIVERSITY OF PORT HARCOURT}

invaluable environmental services such as control of run-off and prevention of erosion, sustenance of the availability and quality of freshwater, soil conservation, climate change abatement, provision of habitat for wildlife, to mention but a few (Aiyeloja and Chima 2011). Wilson (1988) underscored the importance of trees and observed that the future of posterity should not be sacrificed because of the need of the present generation. Considering the importance of tree species, anything that may cause their loss or reduction, like the activity of man on land, is worth looking into.

Man needs to change his behaviour and activities that cause loss of tree species and environmental degradation. Such change in behaviour will to a large extent be enhanced by an understanding of the impact of different land use practices on tree populations. Although, the natural ecosystem of the University of Port Harcourt has been seriously altered as a result of different land use practices such as construction of roads and buildings, shifting agriculture, clearing for other uses, etc., no study had been carried out to evaluate their impact on tree species populations. The study evaluated and compared tree species composition and populations between locations subjected to different land uses and varying degrees of protection and disturbance.

\section{MATERIALS AND METHODS}

Materials: The materials used included ranging poles, pegs, cutlass, ropes, measuring tape, masking tape, field notes, marker/pen, rubber knee boot, digital camera and Geographic Positioning System Unit.

Study Area and Sites: The study was conducted within the University of Port Harcourt, Nigeria. University of Port Harcourt is located in Obio Akpor Local Government Area of Rivers State. Port Harcourt lies within latitude $4.51{ }^{\circ} \mathrm{N}$ and longitude $7.01{ }^{\circ} \mathrm{E}$ of the equator (NDES 2001). The University of Port Harcourt lies in the humid tropical zone with annual rainfall that ranges from $2000-2470 \mathrm{~mm}$, and an annual temperature ranging from $23^{\circ} \mathrm{C}$ to $32^{\circ} \mathrm{C}$ and $\mathrm{RH}$ recorded ranged $70-90 \%$ (NDES 2001).
The study covered three sites purposively chosen from areas of low, moderate, and high disturbances. The site with low disturbance was chosen from the Biodiversity Conservation Area $\left(4^{0} 53^{\prime} 54^{\prime \prime} \mathrm{N}, 6^{0} 54^{\prime} 58^{\prime \prime}\right.$ E) where unsustainable anthropogenic activities are prohibited. The site with moderate disturbance was selected from an Unprotected Secondary Regrowth $\left(4^{0} 54^{\prime} 28^{\prime \prime} \mathrm{N}, 6^{0} 54^{\prime} 58^{\prime \prime} \mathrm{E}\right)$; while the site with high disturbance was chosen from an Arable Farmland ( $\left.4^{0} 54^{\prime} 23^{\prime \prime} \mathrm{N}, 6^{0} 55^{\prime} 26^{\prime \prime} \mathrm{E}\right)$ (Figure1)

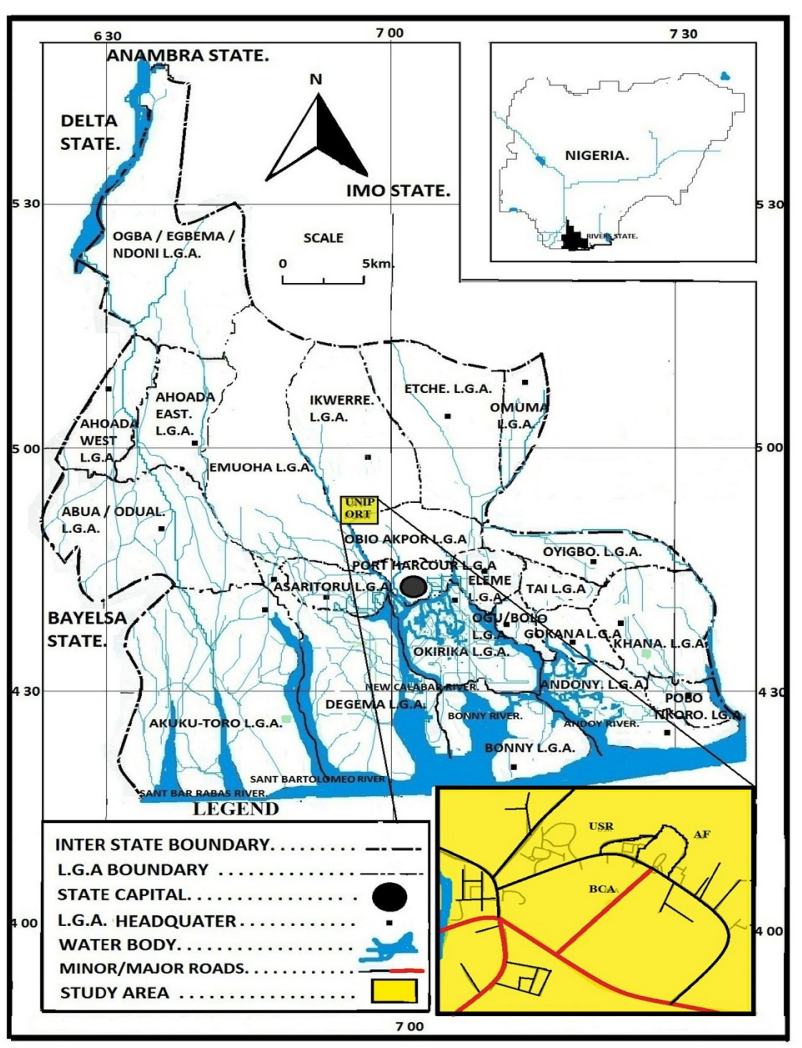

Figure 1: Map of Rivers State showing the study area and the study sites

Tree Enumeration: Five $35 \mathrm{~m} \times 35 \mathrm{~m}$ quadrats were randomly distributed in each of the sites. This quadrat size falls within the range specified in the literature for ecological studies in the humid tropics (Salami 2006). Narrow cut lines were made to demarcate the plot boundaries. Species identification was done with the aid of the keys provided by Keay (1989). All single-stem woody plants of erect posture with a minimum height of $5 \mathrm{~m}$ and diameter at breast height $(\mathrm{dbh})$ of $5 \mathrm{~cm}$ were identified to species level and the number of individuals counted. 
Measurement of alpha diversity: Two common approaches for measuring alpha diversity are species richness and evenness/ heterogeneity (Ojo 1996). Species richness simply refers to the number of species in the community while evenness/heterogeneity refers to the distribution of individuals among the species. In this study, species richness was computed as the total number of tree species encountered in each site. In addition, Margalef Index (Clifford and Stephenson 1975) was also obtained.

\section{Margalef's Index $(\mathrm{ml})=(\mathrm{S}-1) / \ln \mathrm{N}$}

Where:

$\mathrm{S}=$ Number of species

$\mathrm{N}=$ total number of individuals encountered

For the measurement of evenness/ heterogeneity, Simpson Index (Simpson 1949) and Shannon-Wiener Index were computed for each of the sites.

Simpson's Index is expressed as:

$\mathrm{D}=\frac{\sum_{i=1}^{q} n i(n i-1)}{N(N-1)}$

Where:

$\mathrm{N}=$ total number of individuals encountered $\mathrm{ni}=$ number of individuals of ith species enumerated for $i=1 \ldots . . q$

$\mathrm{q}=$ number of different species enumerated.

Shannon-Wiener Index is expressed as:

$\mathrm{H}=-\sum_{i=1}^{s} \mathrm{pi} \log \mathrm{p}$

Where:

pi $=$ the proportion of individuals in the ith species

$\mathrm{s}=$ the total number of species

Computation of tree density: Tree density/ha was computed for individual tree species in each site by dividing a hectare $\left(10,000 \mathrm{~m}^{2}\right)$ with the total area sampled $\left(6,125 \mathrm{~m}^{2}\right)$ and multiplying by the number of individuals of that particular species enumerated in the site. The total tree density for each site was then obtained by adding the densities of all the tree species found in that site.
Evaluation of tree species compositional similarity or variation among land use types Sorensen's similarity index (Pielou 1969) was used to measure the extent of tree species compositional similarity or variation for each pair of the land use types. Wolda (1983) suggested the use of similarity indices for measuring beta diversity.

\section{Sorensen's index is expressed as:}

$\mathrm{SI}=\mathrm{a} /(\mathrm{a}+\mathrm{b}+\mathrm{c}) * 100$

Where:

$\mathrm{a}=$ number of species present in both sites under consideration

$\mathrm{b}=$ number of species present in Site 1 but absent in Site 2

$\mathrm{c}=$ number of species present in Site 2 but absent in Site 1

Measurement of Change in tree populations Change Index (\%) was used to measure the extent of change in the populations of the individual tree species due to land use changes and varying degrees of protection and disturbance. The change index was computed according to Salami (1998); Islam and Weil (2000); and Chima et al. (2009). The calculation of the change index was based on the assumption that the Biodiversity Conservation Area (BCA) is the ideal vegetation in the University of Port Harcourt. Therefore, the number of each tree species in the BCA was taken as an approximation of the optimal number. Consequently, the index of change was derived from the difference between the number of an individual tree species in the BCA and that of each of the USR and AF. The computed difference was then expressed as a percentage of the number in the BCA to obtain the Change Index (\%), which was used either as a degradation index or an improvement index.

\section{RESULTS}

Tree species composition/density at the various land use types

The density of tree species is shown in Tables 1,2 , and 3 for the BCA, USR and AF, respectively. Total tree density was highest in BCA (466 trees/ha), followed by USR (317 trees/hectare), while the Arable farmland had the lowest tree density (73 trees/ha). The density of the individual tree species ranged from $7-124$ trees/hectare in BCA with 


\section{CHIMA UD AND UWAEGBULEM C; TREE SPECIES IN UNIVERSITY OF PORT HARCOURT}

Table 1: Checklist of Tree Species encountered in the Biodiversity Conservation Area and their densities

\begin{tabular}{lll}
\hline Species & Family & $\begin{array}{l}\text { Density } \\
\text { (trees/ha) }\end{array}$ \\
\hline Elaeis guineensis & Palmae & 18 \\
Cassia sieberiana & Leguminosae & 24 \\
Harungana madagascariensis & Guttiferae & 124 \\
Baphia nitida & Leguminosae & 13 \\
Allanblackia floribunda & Guttiferae & 15 \\
Uapaca acuminata & Euphorbiaceae & 49 \\
Pentaclethra macrophylla & Leguminosae & 20 \\
Musanga cecropioides & Moraceae & 34 \\
Spondias mombin & Anacardiaceae & 11 \\
Ficus trichopoda & Moraceae & 8 \\
Ficus exasperata & Moraceae & 11 \\
Gmelina arborea & Verbenaceae & 77 \\
Delonix regia & Leguminosae & 13 \\
Polyalthia sp. & Annonaceae & 31 \\
Leucaena leucocephala & Leguminosae & 11 \\
Raphia hookeri & Palmae & 7 \\
& Total & $\mathbf{4 6 6}$ \\
\hline
\end{tabular}

Table 2: Checklist of tree species enumerated in the Unprotected Secondary Regrowth and their densities

\begin{tabular}{lll}
\hline Species & Family & $\begin{array}{l}\text { Density } \\
\text { (trees/ha) }\end{array}$ \\
\hline Ficus exasparata & Moraceae & 23 \\
Pentaclethra macrophylla & Leguminosae & 24 \\
Harungana madagascariensis & Guttiferae & 41 \\
Funtumia elastica & Apocynaceae & 10 \\
Berlinia grandiflora & Leguminosae & 103 \\
Uapaca acuminata & Euphorbiaceae & 11 \\
Elaeis guineensis & Palmae & 16 \\
Spondias mombin & Anacardiaceae & 47 \\
Ficus sp. & Moraceae & 5 \\
Alstonia boonei & Apocynaceae & 8 \\
Massularia acuminata & Rubiaceae & 24 \\
Polyalthia sp. & Bignoniaceae & 5 \\
& Total & $\mathbf{3 1 7}$ \\
\hline
\end{tabular}

Table 3: Checklist of tree species encountered in the Arable Farm and their Densities

\begin{tabular}{lll}
\hline Species & Family & $\begin{array}{l}\text { Density } \\
\text { (trees/ha) }\end{array}$ \\
\hline Pentraclethra macrophylla & Leguminosae & 8 \\
Spondias mombin & Anacardiaceae & 18 \\
Harungana madagascariensis & Guttiferae & 7 \\
Ficus exasparata & Moraceae & 2 \\
Elaeis guineensis & Palmae & 31 \\
Newbouldia laevis & Bignoniaceae & 2 \\
Gmelina arborea & Verbenaceae & 2 \\
Alstonia boonei & Apocynaceae & 3 \\
& Total & $\mathbf{7 3}$ \\
\hline
\end{tabular}

Harungana madagascariensis being the most abundant. Individual tree species density in USR ranged from $5-103$ trees/ha with Berlinia grandiflora having the highest value; while it ranged from 2 - 31 trees/ha in AF, with E. guineensis having the highest density. The actual number of trees enumerated from which the densities were extrapolated is shown in Table 4.
Table 4: Number of Individuals of tree species enumerated at different Land Use Types

\begin{tabular}{llll}
\hline Species & \multicolumn{3}{l}{ Number of individuals } \\
\cline { 2 - 4 } & BCA & USR & AF \\
\hline Elaeis guineensis & 11 & 10 & 19 \\
Cassia sieberiana & 15 & 0 & 0 \\
Harungana madagascariensis & 76 & 25 & 4 \\
Baphia nitida & 8 & 0 & 0 \\
Allablackia floribunda & 9 & 0 & 0 \\
Uapaca acuminata & 30 & 7 & 0 \\
Pentaclethra macrophylla & 12 & 15 & 5 \\
Musanga cecropioides & 21 & 0 & 0 \\
Spondias mombin & 7 & 29 & 11 \\
Ficus trichopoda & 5 & 0 & 0 \\
Ficus exasperata & 7 & 14 & 1 \\
Gmelina arborea & 47 & 0 & 1 \\
Delonix regia & 8 & 0 & 0 \\
Polyalthia sp. & 19 & 3 & 0 \\
Leucaena leucocephala & 7 & 0 & 0 \\
Raphia hookeri & 4 & 0 & 0 \\
Berlinia grandiflora & 0 & 63 & 0 \\
Funtumia elastica & 0 & 6 & 0 \\
Alstonia boonei & 0 & 5 & 2 \\
Massularia acuminata & 0 & 15 & 0 \\
Ficus sp. & 0 & 3 & 0 \\
Newbouldia laevis & 0 & 0 & 1 \\
Total & 286 & 195 & 44 \\
& & &
\end{tabular}

\section{Distribution of tree species among families} at the various land use types

The distribution of the enumerated tree species among plant families is shown in Figure 2. The family - Leguminosae had the highest number of species in BCA, while the families Moraceae, Leguminosae and Apocynaceae, had the highest number of species in USR. All the species encountered in AF belong to different families.

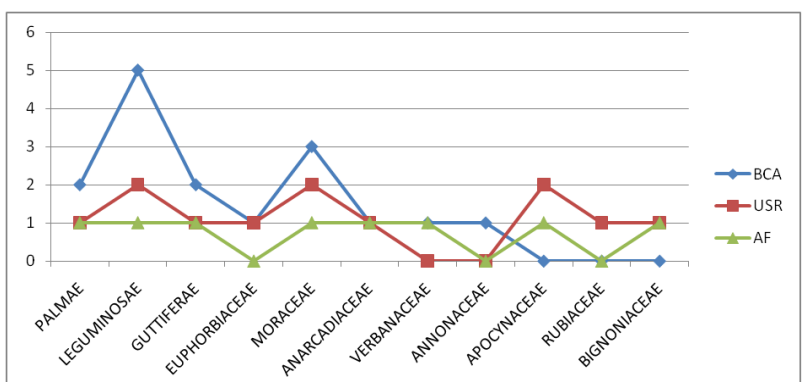

Figure 2: Distribution of tree species among families in the three land use types

\section{Tree diversity at the various land use types}

The alpha diversity indices for the different land use types are shown in Table 5. All indices indicate that the BCA is the most diverse, followed by the USR and the AF respectively. 
Table 5: Alpha Diversity Indices for the different Land Use Types

\begin{tabular}{llll}
\hline & BCA & USR & AF \\
\hline Taxa S & 16 & 12 & 8 \\
Dominance D & 0.1293 & 0.1659 & 0.2738 \\
Shannon H & 2.3820 & 2.0970 & 1.5730 \\
Simpson 1 - D & 0.8707 & 0.8341 & 0.7262 \\
Margalef & 2.6520 & 2.0860 & 1.8500 \\
\hline
\end{tabular}

Table 6: Sorensen's Similarity Indices for the different Land Use Types

\begin{tabular}{llll}
\hline & BCA & USR & AF \\
\hline BCA & $*$ & 33.33 & 33.33 \\
USR & & $*$ & 42.85 \\
AF & & & $*$ \\
\hline
\end{tabular}

Tree species compositional similarity/ dissimilarity amongst land use types

Tree species compositional variation for each pair of the sites is shown in Table 6. The highest variation (66.67) was observed between BCA and each of USR and AF. However, the level of variation (57.15) was lower between USR and AF.

\section{Extent of change in tree populations at the unprotected sites}

The indices of change in tree populations at the two unprotected sites (USR and AF) are presented in Table 7. Cassia sieberiana,

Table 7: Indices of change in the number of tree species at the Unprotected Secondary Regrowth and the Arable Farmland

\begin{tabular}{llll}
\hline Species & \multicolumn{3}{l}{ Change Index (\%) } \\
\cline { 2 - 4 } & BCA & USR & AF \\
\hline Elaeis gueneensis & - & 9.09 & $-72.73^{*}$ \\
Cassia sieberiana & - & 100.00 & 100.00 \\
Harungana madagascariensis & - & 67.11 & 94.74 \\
Baphia nitida & - & 100.00 & 100.00 \\
Allanblackia floribunda & - & 100.00 & 100.00 \\
Uapaca acuminata & - & 76.67 & 100.00 \\
Pentaclethra macrophylla & - & $-25.00^{*}$ & 58.33 \\
Musanga cecropioides & - & 100.00 & 100.00 \\
Spondias mombin & - & $-314.29 *-57.14^{*}$ \\
Ficus trichopoda & - & 100.00 & 100.00 \\
Ficus exasperata & - & $-100^{*}$ & 85.71 \\
Gmelina arborea & - & 100.00 & 97.87 \\
Delonix regia & - & 100.00 & 100.00 \\
Polyalthia sp. & - & 84.21 & 100.00 \\
Leucaena leucocephala & - & 100.00 & 100.00 \\
Raphia hookeri & - & 100.00 & 100.00 \\
Berlinia grandiflora & - & $63^{+}$ & 0.00 \\
Funtumia elastica & - & $6^{+}$ & 0.00 \\
Alstonia boonei & - & $5^{+}$ & $2^{+}$ \\
Massularia acuminata & - & $15^{+}$ & 0.00 \\
Newbouldia laevis & - & 0.00 & $1^{+}$ \\
Ficus sp. & - & $3^{+}$ & 0.00 \\
\hline
\end{tabular}

*- index indicates a corresponding percentage increase in the number of the species at the USR or AF in relation to the number of that species at the $\mathrm{BCA}^{+}$Not actually a change index but the number of individuals of the species encountered where the species is absent in BCA
Baphia nitida, Allanblackia floribunda, Musanga cecropioides, Ficus trichopoda, Delonix regia, Leucaena leucocephala and Raphia hookeri had the highest degradation index $(100 \%)$ in the two unprotected sites. Spondias mombin had the highest improvement index $(314.29 \%)$ in USR while Elaeis guineensis had the highest improvement index in $\mathrm{AF}(72.73 \%)$.

\section{DISCUSSION}

Tree species richness was higher in the Biodiversity Conservation Area than each of the unprotected sites. The level of dissimilarity in tree species composition between each pair of the land use types was generally high, although higher when the Biodiversity Conservation Area was compared with each of the unprotected sites than when the two unprotected sites were compared. Seven tree species were common to BCA and USR; nine species found in BCA were not found in USR while five species found in USR were not found in BCA. Six species were common to $\mathrm{BCA}$ and $\mathrm{AF}$; ten species found in BCA were not found in $\mathrm{AF}$ while only one species found in AF was not present in BCA. Six species were also common to USR and AF. Also six species found in USR were not found in AF while two species found in AF were not found in USR. The dissimilarity may be as a result of different land uses and degrees of disturbance going on in the various sites. It was observed in this study that tree species richness decreased with an increasing level of disturbance with the $\mathrm{BCA}$ and the AF representing the least and highest degrees of disturbance, having the highest and lowest number of tree species respectively. Ihuma et al (2011) noted that habitat fragmentation and subsequent disturbance can bring about changes in tree species composition by encouraging the growth and colonization of disturbed sites by pioneer species. Williams-Linera (1990), also observed that habitat fragmentation may change species composition due to the arrival of new species.

The fact that most of the species encountered in the sites (including the BCA), are pioneer species indicates general disturbances previously. However, the higher species richness in the BCA than in both the USR and the $\mathrm{AF}$ underscores the restorative and 


\section{CHIMA UD AND UWAEGBULEM C; TREE SPECIES IN UNIVERSITY OF PORT HARCOURT}

regenerating ability of disturbed forests when protected from further disturbances from anthropogenic activities. However, tree species richness and diversity in the BCA was lower when compared with those obtained in a similar study conducted in a Nigerian montane forest reserve by Ihuma et al (2011). The family Leguminosae had the highest number of species in BCA, while the families - Moraceae, Leguminosae and Apocynaceae, had the highest number of species in USR. All the species encountered in AF belong to different families.

The highest and lowest tree diversity recorded for the $\mathrm{BCA}$ and $\mathrm{AF}$ respectively reflects the level of protection enjoyed by the two sites and the consequent level of exploitation and resource utilization. Anthropogenic activities are checked in the BCA unlike in the USR and the AF. While the USR was lying fallow, most parts of AF were under arable cropping. Therefore, the lowest tree diversity recorded in AF could be attributed to greatest disturbance arising from the activities associated with arable cropping such as slashing and burning of vegetation. Farm clearing and shifting agriculture are presumed to be the major causes of the formation of the savannas and deforestation we see today in Africa (Barlett 1956).

The improvement in the populations of $S$. mombin and E. guineensis in the unprotected sites could be attributed to the vital roles they play in the livelihoods of the rural dwellers. $S$. mombin is highly valued in the study area because of its edible fruits and medicinal attributes. It also grows easily from cuttings/ stakes. The juice of $S$. mombin is drunk by a woman who had put to bed to hasten the release of delayed placenta and the leaves are also fed to goats with delayed release of placenta to accelerate its release; bark decoction is used to cure palpitation and as eye drops to treat conjunctivitis, trachoma, iritis, ophthalmia, inter alia; while the leaf decoction or leaf juice is used to treat gonorrhea, stomach ache, diarrhea, dysentery, cough, sore throat, bronchitis and related ailments (Etukudo 2003). On the other hand, palm oil, palm kernel oil and other produce from E. guineensis contribute immensely to rural livelihoods. As a result, the rural dwellers tend to favour and encourage the growth of these species. Chima et al (2011) equally attributed the dominance of E. guineensis in an agricultural landscape in Ogoni Land, Rivers State, to its multipurpose nature and the fact that important produce like palm oil, palm kernel, palm kernel oil, and materials for making basket, broom, and fencing are derived from it. The above reasons probably explain why $E$. guineensis and $S$. mombin accounted for about $68 \%$ of the total tree populations in the AF.

\section{CONCLUSION}

The study showed that tree density, richness and alpha diversity decrease with an increasing level of habitat disturbance, and that habitat disturbance through land use changes, could cause alterations in tree species composition of an area. Although, populations of many individual tree species were drastically reduced or completely lost in the unprotected sites, the populations of $S$. mombin and E. guineensis improved considerably in USR and $\mathrm{AF}$ respectively from what were observed in BCA. Enrichment planting and agroforestry were suggested for the re-introduction of tree species in the degraded areas including the arable farmlands.

\section{REFERENCES}

Aiyeloja AA and Chima UD 2011 The Forest: A cornucopia of essential environmental services. pp. 517 - 522. In: Popoola, L.; Ogunsanwo, K; Idumah, F.O. (eds.). Forestry in the Context of the Millennium Development Goals, Vol. 2. Proceedings of the 34th Annual Conference of the Forestry Association of Nigeria (FAN), held in Osogbo, Osun State, $5^{\text {th }}$ to $10^{\text {th }}$ December, 2011

Bartlett HH 1956 Fire, primitive agriculture and grazing in the tropics. pp. 692-720. In: Thomas WL (ed.). Man's role in changing the face of the earth, Chicago.

Chima UD, Ola-Adams BA, Adedire MO and Oyelowo OJ 2009 Impacts of land use changes on soil quality of a biosphere reserve in Southwestern Nigeria. $J$. of Research in Forestry, Wildlife and Envr. 1(1): 120 - 131.

Chima UD, Kamalu OJ and Omokhua GE 2011 Comparative assessment of floral and faunal diversity of two proposed project sites in the Niger Delta region of Nigeria International Journal of Plant, Animal and Environmental Sciences 1(2): 55-62. 
Clifford HT and Stephenson W 1975 An Introduction to Numerical Classification. Academic Press, London, England.

Ehrlich PR and Wilson EO 1991 Biodiversity studies, science and policy. Science 253: 758762.

Etukudo I 2003 Ethnobotany: Conventional and Traditional Uses of Plants. The Verdict Press, Uyo-Nigeria. 191pp.

Harris LD 1984 The Fragmented Forest: Island Biogeography Theory and the Preservation of Biotic Diversity. University of Chicago Press, Chicago.

Ihuma JO, Chima UD and Chapman HM 2011 Tree Species diversity in a Nigerian montane forest ecosystem and adjacent fragmented forest, ARPN Journal of Agricultural and Biological Science 6(2): 17 -22.

Islam KR and Weil RR 2000 Land use effects on soil quality in tropical forest ecosystem of Bangladesh. Agriculture, Ecosystems and Environment, 79: 9 - 16.

Keay RWJ 1989 Trees of Nigeria, Clarendon Press, Oxford, 475pp.

NDES 2001 Biological Environmental Research Report, Rivers State University of Science and Technology (RSUST), Port Harcourt, Vol. 46: 251.

Ojo LO 1996 Data collection and analysis for biodiversity conservation. pp. 142-162. In:

Ola-Adams BA and Ojo LO (eds.) Proceedings of the Inception of a Training Workshop on Biosphere Reserves for Biodiversity Conservation and Sustainable Development in
Anglophone Africa (BRAAF): Assessment and Monitoring Techniques in Nigeria, 9- 11 January, 1996.

Pielou EE 1969 An Introduction to Mathematical Ecology. Wiley-Interscience, New York.

Raven P 1988 Biological resources and global stability. pp 3-27. In: Kawno S, Connell JH and Hidaka T (eds.). Evolution and Co-adaptation in Biotic Communities, University of Tokyo press, Tokyo.

Salami AT 1998 Vegetation modification and man -induced environmental change in rural southwestern Nigeria. Agriculture, Ecosystems and Environment. 70: 159 - 167.

Salami AT 2006 Monitoring Nigerian Forest with NigeriaSat-1 and other satellites. pp $28-61$. In: Salami AT (ed.). Imperatives of Space Technology for Sustainable Forest Management. Proceedings of an International Stakeholders' Workshop Sponsored by National Space Research and Development Agency (NARSDA), Abuja.

Simpson EH 1949 Measurement of diversity. Nature 163:688.

William-Linera G 1990 Vegetation structure and environmental conditions of forest edges, Journal of Ecology. 78: 356 - 373.

Wilson EO 1988 The current state of biological diversity. pp 3-18. In: Wilson EO and Peter FM (eds.) Biodiversity. Natural Academy Press, Washington D.C.

Wolda H 1983 Diversity, diversity indices and tropical cockroaches. Oecologia 58:290-298. 